A Molecular Dynamics Study of Chemical Reactions of Solid Pentaerythritol Tetranitrate at Extreme Conditions

C. J. Wu, M. R. Manaa, L. E. Fried

June 1, 2006 
This document was prepared as an account of work sponsored by an agency of the United States Government. Neither the United States Government nor the University of California nor any of their employees, makes any warranty, express or implied, or assumes any legal liability or responsibility for the accuracy, completeness, or usefulness of any information, apparatus, product, or process disclosed, or represents that its use would not infringe privately owned rights. Reference herein to any specific commercial product, process, or service by trade name, trademark, manufacturer, or otherwise, does not necessarily constitute or imply its endorsement, recommendation, or favoring by the United States Government or the University of California. The views and opinions of authors expressed herein do not necessarily state or reflect those of the United States Government or the University of California, and shall not be used for advertising or product endorsement purposes.

This work was performed under the auspices of the U.S. Department of Energy by University of California, Lawrence Livermore National Laboratory under Contract W-7405-Eng-48. 


\title{
A MOLECULAR DYNAMIC STUDY OF CHEMICAL REACTIONS OF SOLID PENTAERYTHRITOL TETRANITRATE AT EXTREME CONDITIONS
}

\author{
Christine J. Wu, M. Riad Manaa and Laurence E. Fried
}

Lawrence Livermore National Laboratory

\begin{abstract}
We have carried out density functional based tight binding (DFTB) molecular dynamics (MD) simulation to study energetic reactions of solid Pentaerythritol Tetranitrate (PETN) at conditions approximating the Chapman-Jouguet (CJ) detonation state. We found that the initial decomposition of PETN molecular solid is characterized by uni-molecular dissociation of the $\mathrm{NO}_{2}$ groups. Interestingly, energy release from this powerful high explosive was found to proceed in several stages. The large portion of early stage energy release was found to be associated with the formation of $\mathrm{H}_{2} \mathrm{O}$ molecules within a few picoseconds of reaction. It took nearly four times as long for majority of $\mathrm{CO}_{2}$ products to form, accompanied by a slow oscillatory conversion between $\mathrm{CO}$ and $\mathrm{CO}_{2}$. The production of $\mathrm{N}_{2}$ starts after $\mathrm{NO}_{2}$ loses its oxygen atoms to hydrogen or carbon atoms to form $\mathrm{H}_{2} \mathrm{O}$ or $\mathrm{CO}$. We identified many intermediate species that emerge and contribute to reaction kinetics, and compared our simulation with a thermo-chemical equilibrium calculation. In addition, a detailed chemical kinetics of formation of $\mathrm{H}_{2} \mathrm{O}, \mathrm{CO}$, and $\mathrm{CO}_{2}$ were developed. Rate constants of formations of $\mathrm{H}_{2} \mathrm{O}, \mathrm{CO}_{2}$ and $\mathrm{N}_{2}$ were reported.
\end{abstract}




\section{INTRODUCTION}

There is considerable interest in unraveling details of the chemical reactions that occur in solid energetic materials that consist of molecules of $\mathrm{H}, \mathrm{C}, \mathrm{N}$ and $\mathrm{O}$ atoms. Examples of high explosives in this class of importance are PETN, HMX, RDX and TATB. Among them, PETN is one of most powerful and brisant explosive. It is well understood that the major gas phase detonation products of these high explosives are $\mathrm{H}_{2} \mathrm{O}, \mathrm{CO}_{2}$ and $\mathrm{N}_{2}$, which represent the most stable compounds likely made of $\mathrm{H}, \mathrm{C}, \mathrm{N}$ and $\mathrm{O}$. However, understanding of the detailed steps involved in those condensed phased reactions has continued to be an area of active research.[1] Kinetic experiments, such as manometric technique and time history of weight loss upon heating provide description of reaction kinetics at the phenomenological level. However, these simple models are generally not transferable in a wide range of densities and temperatures. In fact, previous studies of PETN decomposition reactions have reached no general agreement as to the decomposition and recombination reactions. For example, the reported activation energies of PETN decomposition are scattered from 30 to $70 \mathrm{kcal} / \mathrm{mol}$.[1-4] Chemical analysis of decomposition residue was able to reveal small portion of reaction intermediates. There is general agreement that the first decomposition step is the breaking of the O- $\mathrm{NO}_{2}$ bond.[3-5] However, direct experimental probes of chemical kinetics occurring in the detonation of solid phase explosives are not yet available. Molecular dynamics (MD) simulations provide alternative avenues to study chemical kinetics at extreme conditions. MD simulations allow for atomistic studies of reactions, which are essential for developing physics-based and predictive kinetic models of energetic materials.

There are a few reasons why PETN is well suited for MD simulations. In comparison to other high explosives in this class, PETN is the most sensitive energetic material upon external stimuli, and yields rapid decomposition reactions. It is also oxygen rich and generates little solid carbon that takes nanosecond to precipitate. Thus, there is a

possibility that one can observe the wide range of reactions of PETN from its initial decomposition to later near equilibrium stage in one MD simulation. In this work, we 
report the results of an MD simulation of a PETN solid at the Chapman-Jouguet (CJ) condition of complete reactivity, which correspond to a density of $2.39 \mathrm{~g} / \mathrm{cc}$ and temperature of $\mathrm{T}=4200 \mathrm{~K}$. The $\mathrm{CJ}$ condition refers to the sonic point behind the detonation wave where chemical equilibrium is established, an example of an extreme condition. However, our simulations were carried out in a constant NVT ensemble, which is more comparable to a heated diamond anvil cell condition than a shock condition. The focus of this work is to unravel the nature of PETN decomposition, as well as the key steps involved in formations of its final product. We believe such kinetic information is transferable to other high density and temperature conditions.

\section{COMPUTATIONAL DETAILS}

The essential input of any MD simulation is the inter-atomic forces that govern the motion of ions by Newton's equation. In this work, we employed the inter-atomic interaction determined by the self-consistent charge density-functional tight binding (SCC-DFTB) method. This method incorporates a self-consistent charge mode into the two-center and non-orthogonal Tight-Binding (TB) theory based on a second-order expansion of the Kohn-Sham total-energy functional as calculated within DFT.[6] This charge dependent energy contribution improves chemical transferability significantly, resulting in improved values of reaction energies for many organic molecules and biomolecules containing $\mathrm{H}, \mathrm{C}, \mathrm{O}$ and $\mathrm{N}$. [7] In this work, we used the DFTB parameters employed in the previous studies of thermal decomposition of the explosive HMX and nitromethane .[8-9]

We studied the decomposition of PETN in a constant NVT ensemble ( $T=4200 \mathrm{~K}$ and $\rho=2.39 \mathrm{~g} / \mathrm{cc}$ ). The initial state of simulation was constructed by scaling the experimental PETN crystal lattice parameters hydrostatically with ambient molecular structure to achieve desired density. This geometry was then subsequently optimized with DFTB before the MD simulation. All simulations were carried out with 3D periodic boundary condition. The time step of $0.48 \mathrm{fs}(20 \mathrm{au})$ was used in all stimulations and snapshots 
were collected at every 20 steps (9.6 fs) for post simulation analysis. Results, such as average lifetime of a species were time averaged over $71 \mathrm{ps.}$

The crystal structure of PETN was previously determined by X-ray chromatography to be in the space group of $P \overline{4} 2_{1} c .[10-11]$ Our simulation cell contains 4 PETN molecules (116 atoms, displayed in Figure 1(a)). In order to check the effect of simulation cell size, we have also carried out a short run (4.5ps) of a large simulation cell of 8 PETN molecules (232 atoms, displayed in Figure 1(b)). Comparing simulation results of $g(r)$ and time histories of major reaction products from those two different simulation cell sizes, we found remarkable resemblance. We also found that the larger the simulation cell, the lesser the magnitude of fluctuations in our statistics. There is no significant/qualitative difference observed beyond statistical noises. The lack of strong dependence of simulation cell size is consistent with the uni-molecular nature of PETN decomposition discovered from our post simulation analysis (see details in section III).

For each snapshot, we define instantaneous species using a molecular identifier based on a set of bond distance criteria determined by the first minimum in radial distribution functions $g(r)$ for most of pairs. For instance, Fig. 2 shows the radial distribution functions $g(r)$ of $\mathrm{C}-\mathrm{C}, \mathrm{C}-\mathrm{N}, \mathrm{C}-\mathrm{H}, \mathrm{C}-\mathrm{O}, \mathrm{N}-\mathrm{H}, \mathrm{N}-\mathrm{N}, \mathrm{O}-\mathrm{H}$ and $\mathrm{O}-\mathrm{N}$ pairs and its corresponding cutoff of the covalent bond distance, respectively. However, since there was no significant covalent bond formation between $\mathrm{O}-\mathrm{O}$ and $\mathrm{H}-\mathrm{H}$, the first peak in $g(r)$ of $\mathrm{O}-\mathrm{O}$ and $\mathrm{H}-\mathrm{H}$ does not correspond to their mean covalent bond distance, but rather to the mean distance of two oxygen atoms in $\mathrm{NO}_{2}$ molecules and that of two hydrogen atoms in $\mathrm{H}_{2} \mathrm{O}$ molecules, respectively. Thus, in these two cases, we used the averaged covalent radii plus an additional correction term of $15 \%$, estimated for enlarged bond stretch at the high temperature of $4200 \mathrm{~K}$. Like any molecular identifiers of distancebased, this identifier has no ability to screen out transient fly-by configurations that do not belong to stable intermediates. However, we do not expect this shortcoming to give rise to significant error bars on averaged concentration of species, since the life times of those transient configurations are typically extremely short. 


\section{RESULTS AND DISCUSSIONS}

There are many instantaneous species being formed during the simulations. For our long 71 ps simulation, there are over 900 species identified in total. However, significant portion of them are short-lived transient configurations. For instance, roughly half of 900 species only existed for one step in our simulation. About 39 species appears in 5\% of simulation. We show in Fig. 3 the relative lifetime of the top 20 most populated species, which was found to be insensitive to slight modifications of cutoff distances by $\pm 1 \%$ of molecular identifier. These species are likely to be intermediates of importance. However, it is difficult to uncover the reaction kinetics between species by using concentration profiles alone. Unfortunately, we found that most effect way of uncovering reaction kinetics is to follow snapshots of simulation step by step manually.

By reviewing the snapshots, we found that the initial step of PETN dissociation is unimolecular (see Fig. 4). There are no bimolecular interactions with neighboring molecules observed for PETN, in contrast to other high explosives, such as HMX and TATB. Notice that the PETN molecule has four identical branches bonded in a near tetrahedron arrangement, with $\mathrm{O}-\mathrm{NO}_{2}$ groups at its outside shell, five $\mathrm{C}$ atoms in its core, and $\mathrm{H}$ atoms in between. The uni-molecular pathway is consistent with the PETN geometry where $\mathrm{H}$ atoms are less accessible to the outside $\mathrm{O}-\mathrm{NO}_{2}$ groups of its neighbors. We observed that the primary decomposition pathway is $\mathrm{O}-\mathrm{NO}_{2}$ rupture. Small numbers of C$\mathrm{ONO}_{2}\left(\mathrm{NO}_{3}\right)$ bond dissociations were also observed in parallel. Within the first $10 \mathrm{fs}, 11$ out of 16 available outer $\mathrm{N} / \mathrm{O}$ groups have been dissociated via either $\mathrm{NO}_{2}$ or by $\mathrm{NO}_{3}$. The dissociated $\mathrm{NO}_{3}$ groups were then further converted to $\mathrm{NO}_{2}$ by losing $\mathrm{O}$ to a $\mathrm{H}$ atom on $\left(\mathrm{CH}_{2} \mathrm{NO}_{3}\right)_{3}-\mathrm{C}-\mathrm{CH}_{2}=\mathrm{O}$ to form $\mathrm{OH}$. This observation is consistent with previous experiments, and our previous DFT calculations that $\mathrm{O}-\mathrm{NO}_{2}$ is the weakest bond among other possible bond breakages.[5]

Breakings of $\mathrm{NO}_{2}$ groups have consequently generated an active reaction site on the remaining $\left(\mathrm{CH}_{2} \mathrm{NO}_{3}\right)_{3}-\mathrm{C}-\mathrm{CH}_{2}=\mathrm{O}$ fragments. Notice that the red $\mathrm{C}$ atom in a fragment of $\left(\mathrm{CH}_{2} \mathrm{NO}_{3}\right)_{3}-\mathrm{C}-\mathrm{CH}_{2}=\mathrm{O}$ (shown in Fig. 5(a) and (c)) fails to satisfy its optimal bonding preference of 4 bonds ( 5 bonds were needed for this configuration: C-C, $2 \mathrm{C}-\mathrm{H}$ and 
$\mathrm{C}=\mathrm{O}$ ). As a result, one of $\mathrm{H}$ connected to the red $\mathrm{C}$ becomes highly reactive. In most observed snapshots, it reacts with $\mathrm{NO}_{2}$ to form an intermediate O-N-O-H, which then dissociates into $\mathrm{N}-\mathrm{O}$ and $\mathrm{H}-\mathrm{O}$ (see Fig5 (a)). Next, the $\mathrm{OH}$ fragment reacts with the $\mathrm{H}$ atom on the remaining $\left(\mathrm{CH}_{2} \mathrm{NO}_{3}\right)_{3}-\mathrm{C}-\mathrm{CH}=\mathrm{O}$ fragment to form $\mathrm{H}_{2} \mathrm{O}$. Subsequently, $\left(\mathrm{CH}_{2} \mathrm{NO}_{3}\right)_{3}-\mathrm{C}-\mathrm{C}=\mathrm{O}$ breaks into $\left(\mathrm{CH}_{2} \mathrm{NO}_{3}\right)_{3}-\mathrm{C}$ and $\mathrm{C}=\mathrm{O}$. The simultaneous formation of $\mathrm{H}_{2} \mathrm{O}$ and $\mathrm{CO}$ is displayed in Fig.5 (b). Occasionally, one of the $\mathrm{H}$ atoms bonded to the red $\mathrm{C}$ in $\left(\mathrm{CH}_{2} \mathrm{NO}_{3}\right)_{3}-\mathrm{C}-\mathrm{CH}_{2}=\mathrm{O}$ was also observed to break off to form an $\mathrm{H}$ species, which then proceeds to capture an $\mathrm{OH}$ to form a $\mathrm{H}_{2} \mathrm{O}$ molecule (Fig5(c)). Our simulation clearly suggests that $\mathrm{OH}$ play an important role in the formation of $\mathrm{H}_{2} \mathrm{O}$ and $\mathrm{CO}$ molecules, which has not been suggested previously to the best of our knowledge. In comparison to previous proposed reaction mechanisms developed for low pressure, our kinetics model is remarkably different. In particular, the production of $\mathrm{H}_{2} \mathrm{O}$ takes only three steps in our model. In contrast, the production of $\mathrm{H}_{2} \mathrm{O}$ would takes nine steps in a previous proposed model.[9]

It general, the oxidation of $\mathrm{H}$ atoms to form $\mathrm{H}_{2} \mathrm{O}$ molecules releases a large amount of energy. In contrast, we do not expect formation of $\mathrm{C}=\mathrm{O}$ molecules to contribute much to the energy release, since $\mathrm{C}=\mathrm{O}$ forms largely from breaking off from the $\left(\mathrm{CH}_{2} \mathrm{NO}_{3}\right)_{3}-\mathrm{CH}-$ $\mathrm{C}=\mathrm{O}$ moiety, an exothermic process. Unfortunately, we cannot extract the exact amount of energy release from our simulation, since it was carried out in a thermal bath of a NVT ensemble. Nevertheless, we can estimate the approximated time scale of this fast energy release for this temperature and density condition. For instance, the first $\mathrm{H}_{2} \mathrm{O}$ was observed to form around $0.12 \mathrm{ps}$, and the concentration of $\mathrm{H}_{2} \mathrm{O}$ reaches a plateau roughly after 1ps. Notice that one of PETN explosive's characteristics is its brisance, an ability to shatter surrounding materials. We suggest that the fast formation of $\mathrm{H}_{2} \mathrm{O}$ contributes to the rapidity with which PETN reaches its peak pressure.

The next major gas phase product to form is $\mathrm{CO}_{2}$, which is found to form via $\mathrm{HOCO}$ intermediate by $\mathrm{HO}+\mathrm{CO}--->\mathrm{HOCO}-->\mathrm{H}+\mathrm{OCO}$. Both $\mathrm{H}$ and $\mathrm{HO}$ intermediates play an important role in recombination reactions. Their concentrations remained to be significant during the simulation. The concentrations of $\mathrm{CO}$ and $\mathrm{CO}_{2}$ remain oscillatory 
even after $\mathrm{CO}_{2}$ concentration reaches a relative flat region after $15 \mathrm{ps}$. The presence of $\mathrm{CO}$ was also observed from our previous DFTB simulation of $\mathrm{CO}_{2}$ at high temperatures and densities. We found that the dissociation of $\mathrm{CO}_{2}$ becomes significant when simulation density exceeds $2.4 \mathrm{~g} / \mathrm{cc}$, which is in the approximately same density region as this simulation.

The production of $\mathrm{N}_{2}$ molecules is the slowest process overall. This is due largely to all $\mathrm{N}$ atoms being bonded by $\mathrm{O}$ atoms initially in an unreacted PETN solid. It is only after $\mathrm{H}$ and $\mathrm{C}$ have been oxidized by $\mathrm{O}$ atoms carried by $\mathrm{NO}_{2}$, that the nitrogen atoms have their freedoms to find each other and form N-N bonds. In fact the first $\mathrm{N}_{2}$ forms around 3.2ps, by which $\mathrm{H}_{2} \mathrm{O}$ has nearly completed its formation. It is expected that the formations of $\mathrm{N}_{2}$ molecules generate a fair amount of kinetic energy. $\mathrm{N}_{2}$ production slowly reaches a relatively flat region by the end of our simulation of 71ps.

Figure 7 displays the mole concentrations of $\mathrm{H}_{2} \mathrm{O}, \mathrm{CO}_{2}$ and $\mathrm{N}_{2}$ as a function of time. We

fit those concentration profiles using analytical expression of $c(t)=c_{e q}\left(1-e^{\left(-\left(t-t_{o}\right) / \tau\right)}\right)$, where $t_{o}$ and $c_{e q}$ represent the reaction induction time and the equilibrium concentration, respectively. Rate constants $\tau$ for $\mathrm{H}_{2} \mathrm{O}, \mathrm{CO}_{2}$ and $\mathrm{N}_{2}$ are listed also in Figure 7. It shows a clear separation of time scales, which can be used for a future development of a quantum chemistry-based reaction model for PETN solid. We also compared the final concentration of major species in our simulation against those predicted by the thermal chemistry code Cheetah in Figure 8. One major discrepancy is that there is a lot more CO concentration from our simulation than that of cheetah. In addition, DFTB gives a lot more $\mathrm{H}, \mathrm{HO}$ and $\mathrm{H}_{3} \mathrm{O}$ species, which are not included in Cheetah calculation.

\section{CONCLUSIONS}

In summary, several key facts of PETN dissociation have been revealed via the DFTB molecular dynamics simulation. Overall, its dissociation proceeds from outside $\left(\mathrm{NO}_{2}\right)$ groups to inside carbon core dominated by the molecular geometry of PETN and in unimolecular fashion. The oxidization of $\mathrm{H}, \mathrm{C}$ and $\mathrm{N}$ atoms results in formations of $\mathrm{H}_{2} \mathrm{O}$, $\mathrm{CO}_{2}$ and $\mathrm{N}_{2}$ in relatively distinct time scales. Formation of $\mathrm{H}_{2} \mathrm{O}$ starts almost immediately 
after breaking of $\mathrm{NO}_{2}$ groups, and reaches its completion within a few picoseconds. We believe this fast energy release give arise to its brisance. Although, $\mathrm{CO}$ and $\mathrm{CO}_{2}$ gases forms at early stage as well, it takes a long time to reach its equilibrium and its oscillation lasted during the simulation time of $71 \mathrm{ps}$. By the time that $\mathrm{N}_{2}$ gas production starts, the water production is nearly complete. $\mathrm{N}_{2}$ production is slow which reaches its equilibrium beyond the simulation time of $71 \mathrm{ps}$. We have developed a chemical kinetics model for the formation of $\mathrm{H}_{2} \mathrm{O}, \mathrm{CO}$ and $\mathrm{CO}_{2}$. We have also reported the reaction rate constants for overall productions of $\mathrm{H}_{2} \mathrm{O}, \mathrm{CO}_{2}$ and $\mathrm{N}_{2}$.

\section{ACKNOWLEDGEMENTS}

This work was preformed under the auspices of the U.S. Department of Energy by the University of California, Lawrence Livermore National Laboratory under Contact No. W-7504-Eng-48. Authors would like to thank Dr. S. Bastea for sharing with us his thermo-equilibrium Cheq result and stimulating discussions.

\section{REFERENCES}

1. D. M. Chambers, "Perspectives on Pentaerythritol Tetranitrate (PETN) Decomposition", UCRL-JC-148956.

2. M. Van der Merwe, F. C. Fouche, and M. Von Abo, Proceeding $17^{\text {th }}$ Int. Ann. Conf. Fraunhofer Institut fur Chemische Technologie (ICT), Karsruhe, Germany, 62 (1986).

3. K. K. Andreev and B. I. Kaidymov, Russ. J. Phys. Chem. 35, 1324 (1961).

4. W. L. Ng, J. E. Field and H. M. Hauser, J. Appl. Phys. 59, 3945 (1986).

5. C. J. Wu, F. H. Ree and C. S. Yoo, Prop. Explos. Pyrotech. 29, 296 (2004).

6. M. Elstner, D. Porezag, G. Jungnickel, J. Elsner, M. Hauk, T. Frauenheim, S. Suhai, and G. Seifert, Phys. Rev. B 58 (1998) 7260.

7. M. Elstner, P. Hobza, T. Frauenheim, S. Suhai, and E. Kaxiras, J. Chem. Phys. 114 (2001) 5149.

8. M. R. Manaa, L. E. Fried, C. F. Melius, M. Elstner, and Th. Frauenheim. J. Phys. Chem. A, 106 (2002) 9024. 
9. D. Margetis, E. Kaxiras, M. Elstner, Th. Frauenheim, and M.R. Manaa. J. Chem. Phys. 117(2002).

10. S. E. Klassen, T. M. Massis, E. P. Boespflug ,B. M. Montoya and J. L. Reif, Thermochim. Acta, 6873, 1-13 (2001)

11. H. H. Cady and A. C. Larson, Acta Cryst. B31, 1864 (1975).

12. A. D. Booth and F. J. Llewellyn, J. Chem. Soc. 837, (1947). 
Figure 1. MD snap shots obtained from simulations of sizes of (a) 116 atoms and (b) 238 atoms.

(a)

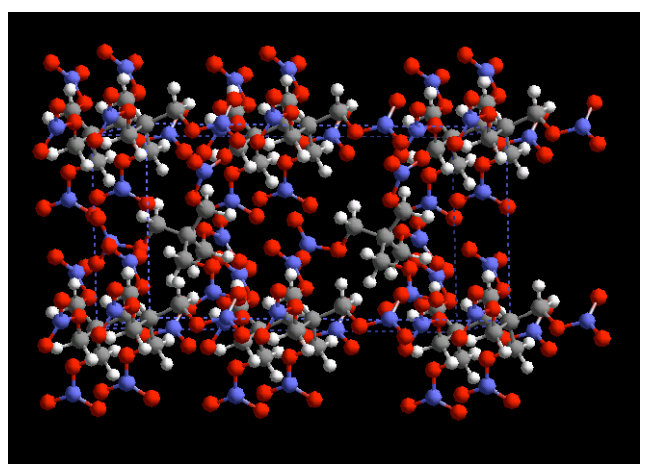

(b)

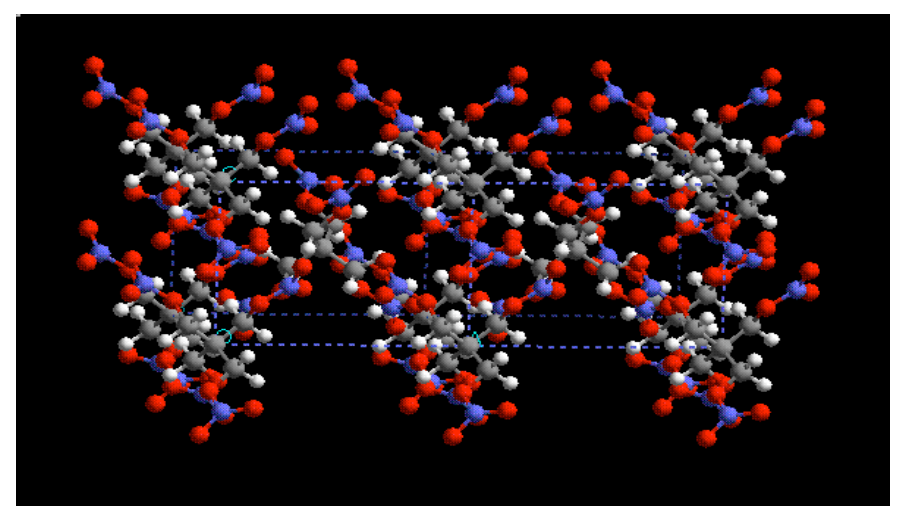


Figure 2. Radial distribution functions g(r) obtained from our DFTB simulations.
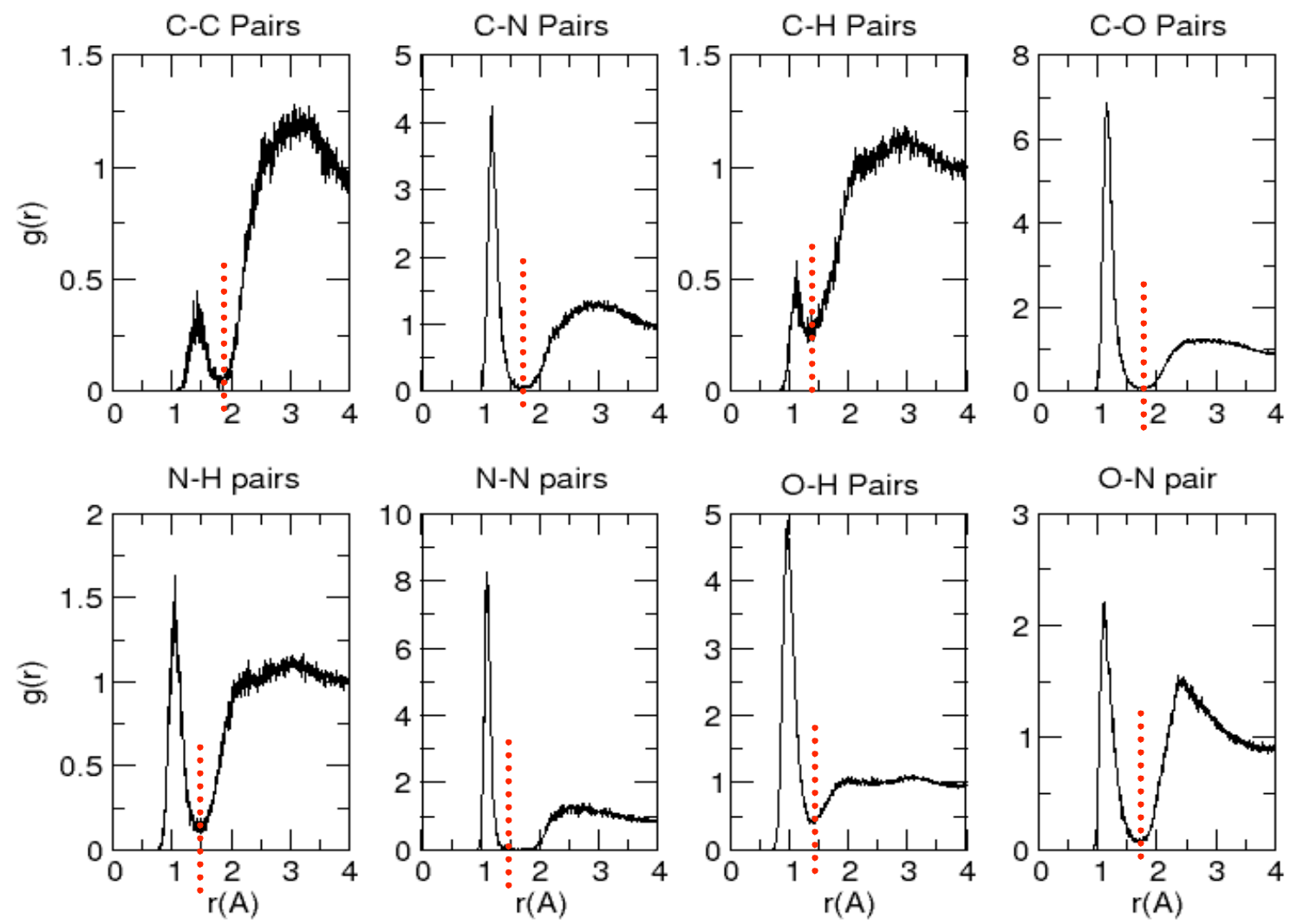
Figure 3. Lifetime of top 20 fragments relative to that of $\mathrm{H}_{2} \mathrm{O}$ observed during simulation time of 32ps. Fragments 1 to 20 represent $\mathrm{H}_{2} \mathrm{O}, \mathrm{CO}_{2}, \mathrm{CO}, \mathrm{NO}, \mathrm{OH}, \mathrm{H}, \mathrm{N}_{2}, \mathrm{O}, \mathrm{HNCO}$, $\mathrm{NCO}, \mathrm{CN}, \mathrm{HOCO}, \mathrm{NO}_{2}, \mathrm{~N}, \mathrm{H}_{3} \mathrm{O}, \mathrm{HCN}, \mathrm{HNC}, \mathrm{NOC}, \mathrm{HOCN}$ and $\mathrm{HCO}$, respectively.

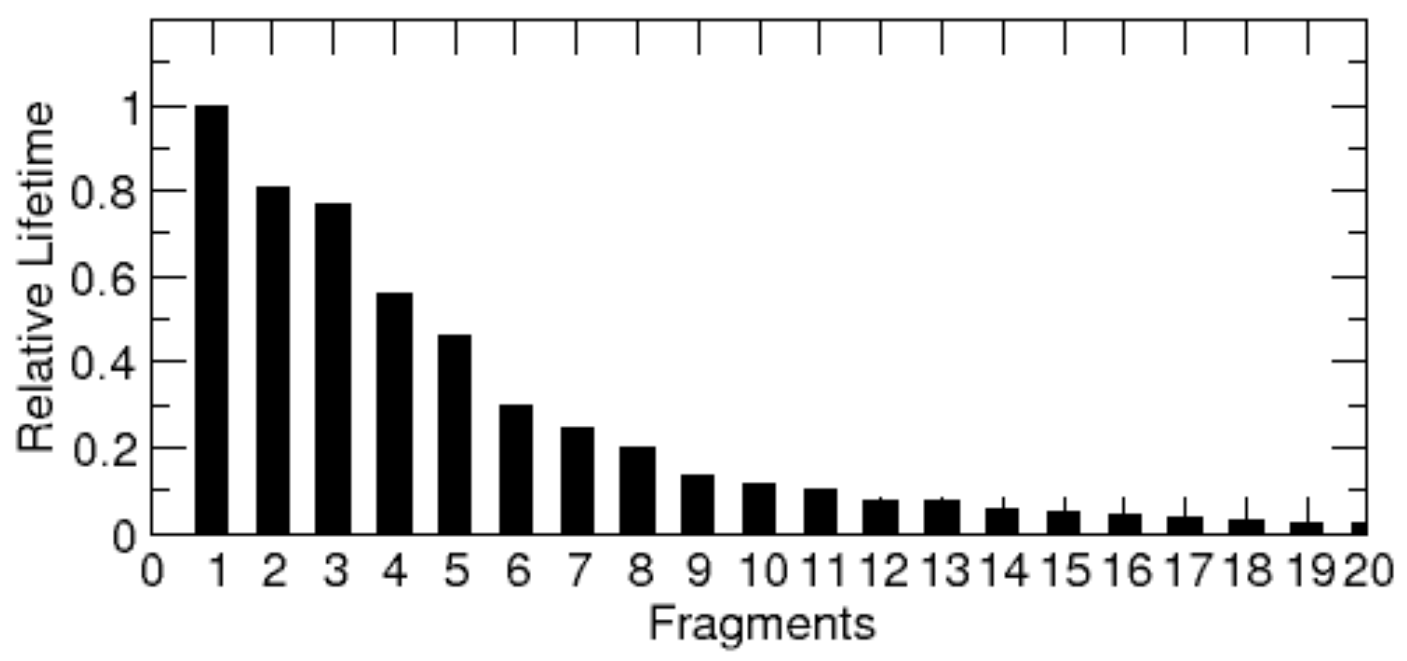


Figure 4. Uni-molcular decomposition pathways of PETN molecular solid.

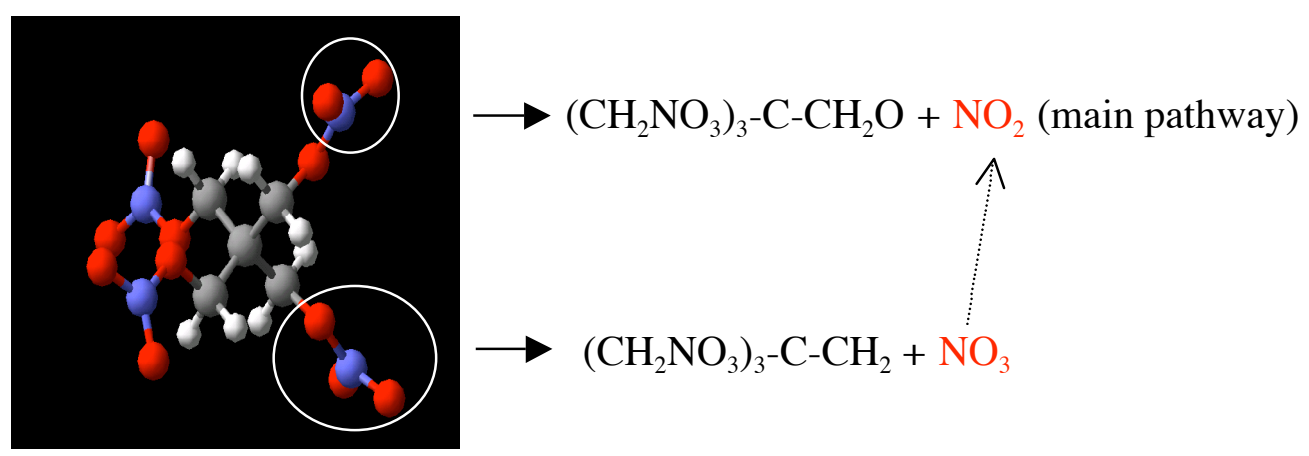


Figure 5. Reaction pathways observed for formation of $\mathrm{H}_{2} \mathrm{O}$ and $\mathrm{CO}$ from DFTB simulations.
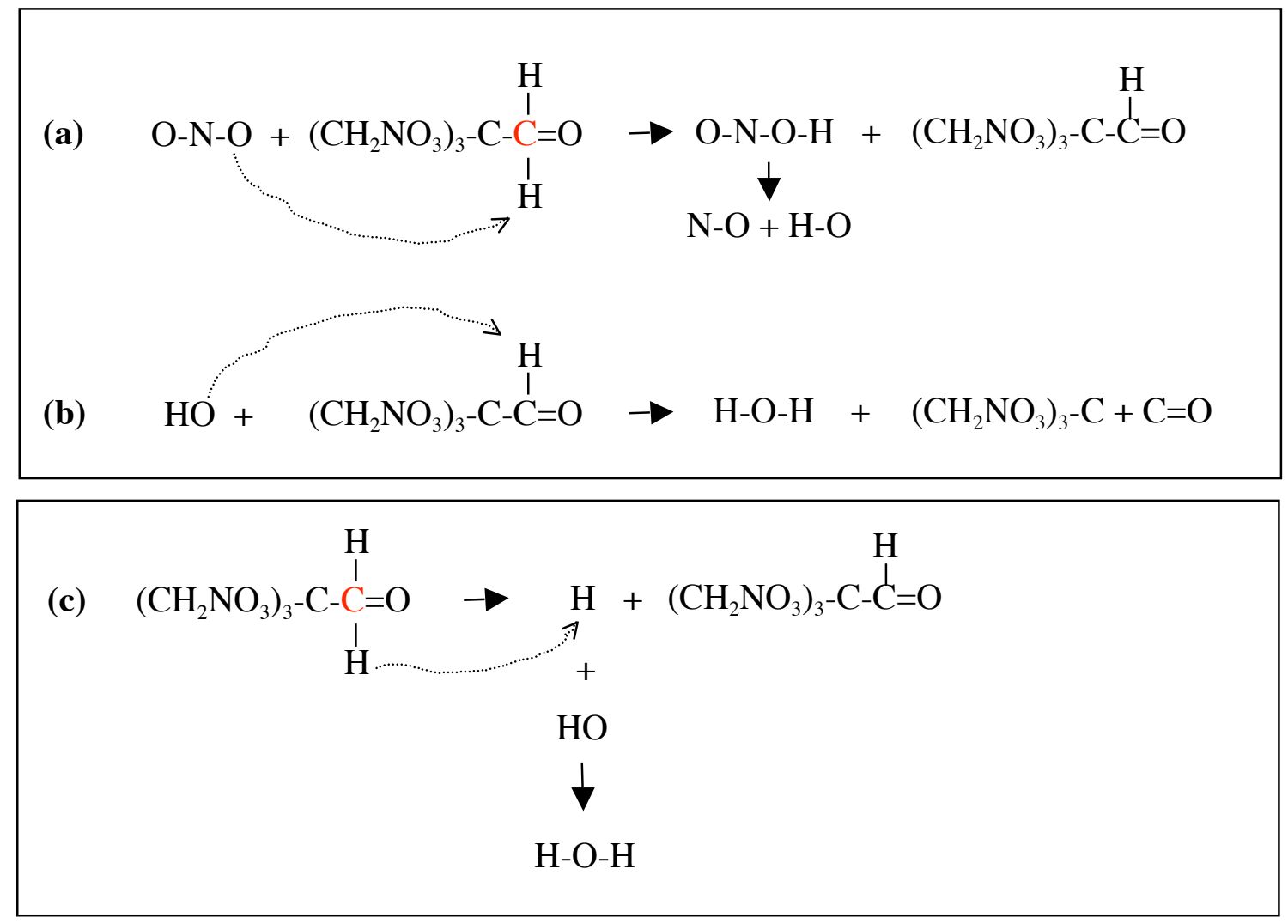
Figure 6. Concentration as a function of simulation time for $\mathrm{H}_{2} \mathrm{O}, \mathrm{CO}_{2}$ and $\mathrm{N}_{2}$ obtained from our DFTB simulations.

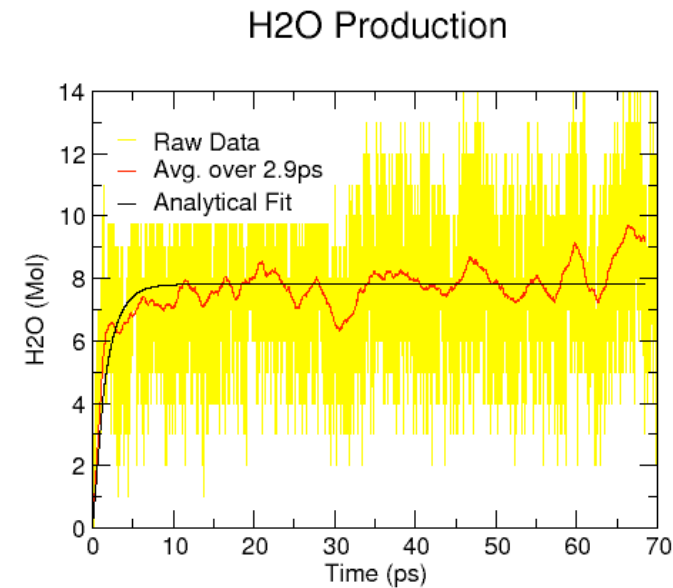

$$
\left.\mathrm{C}(\mathrm{t})=\mathrm{C}_{\mathrm{eq}}\left(1-\exp \left(-\left(\mathrm{t}-\mathrm{t}_{\mathrm{o}}\right) / \tau\right)\right)\right)
$$

$$
\begin{aligned}
& \mathrm{C}_{\text {eq }}=7.8 \mathrm{~mol} \\
& \tau=0.03 \mathrm{ps}
\end{aligned}
$$$$
\mathrm{t}_{\mathrm{o}}=1.7 \mathrm{ps}
$$

\section{CO2 Production}

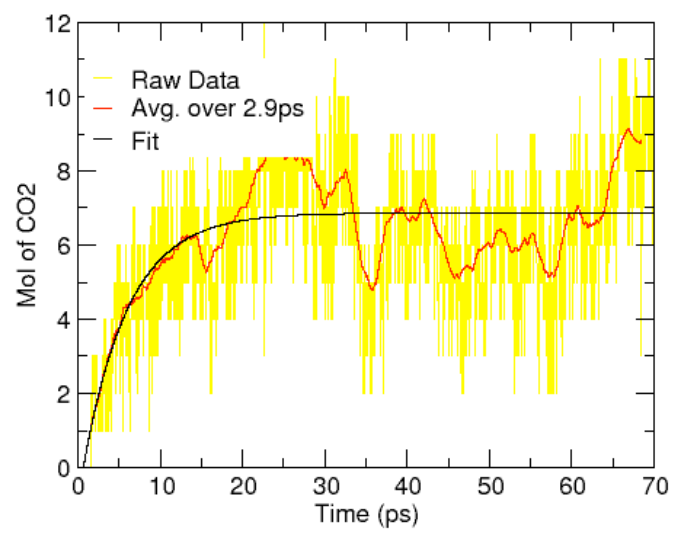

$$
\left.\mathrm{C}(\mathrm{t})=\mathrm{C}_{\mathrm{eq}}\left(1-\exp \left(-\left(\mathrm{t}-\mathrm{t}_{\mathrm{o}}\right) / \tau\right)\right)\right)
$$

$$
\begin{aligned}
& \mathrm{C}_{\mathrm{eq}}=7.53 \mathrm{~mol} \\
& \tau=5.4 \mathrm{ps} \\
& \mathrm{t}_{\mathrm{o}}=0.7 \mathrm{ps}
\end{aligned}
$$

N2 Production

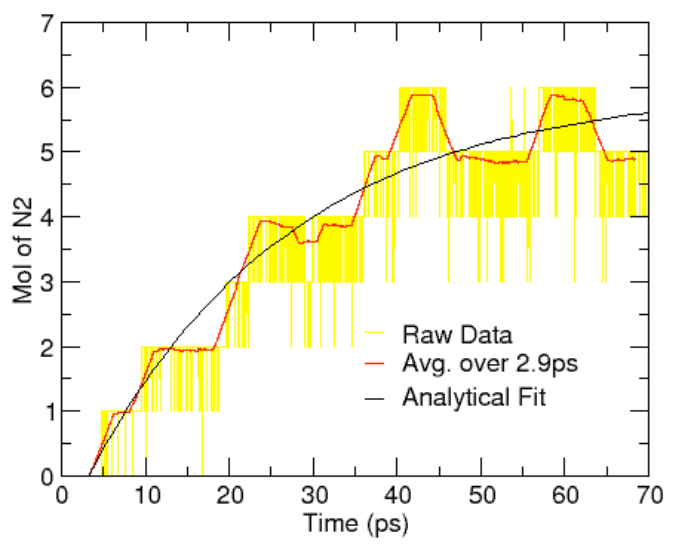

$\left.\mathrm{C}(\mathrm{t})=\mathrm{C}_{\mathrm{eq}}\left(1-\exp \left(-\left(\mathrm{t}-\mathrm{t}_{\mathrm{o}}\right) / \tau\right)\right)\right)$

$$
\begin{aligned}
& \mathrm{C}_{\mathrm{eq}}=6.0 \mathrm{~mol} \\
& \tau=24.3 \mathrm{ps} \\
& \mathrm{t}_{\mathrm{o}}=3.2 \mathrm{ps}
\end{aligned}
$$


Figure 7. Final concentrations of major species obtained from TB MD, and the chemical equilibrium code Cheetah.

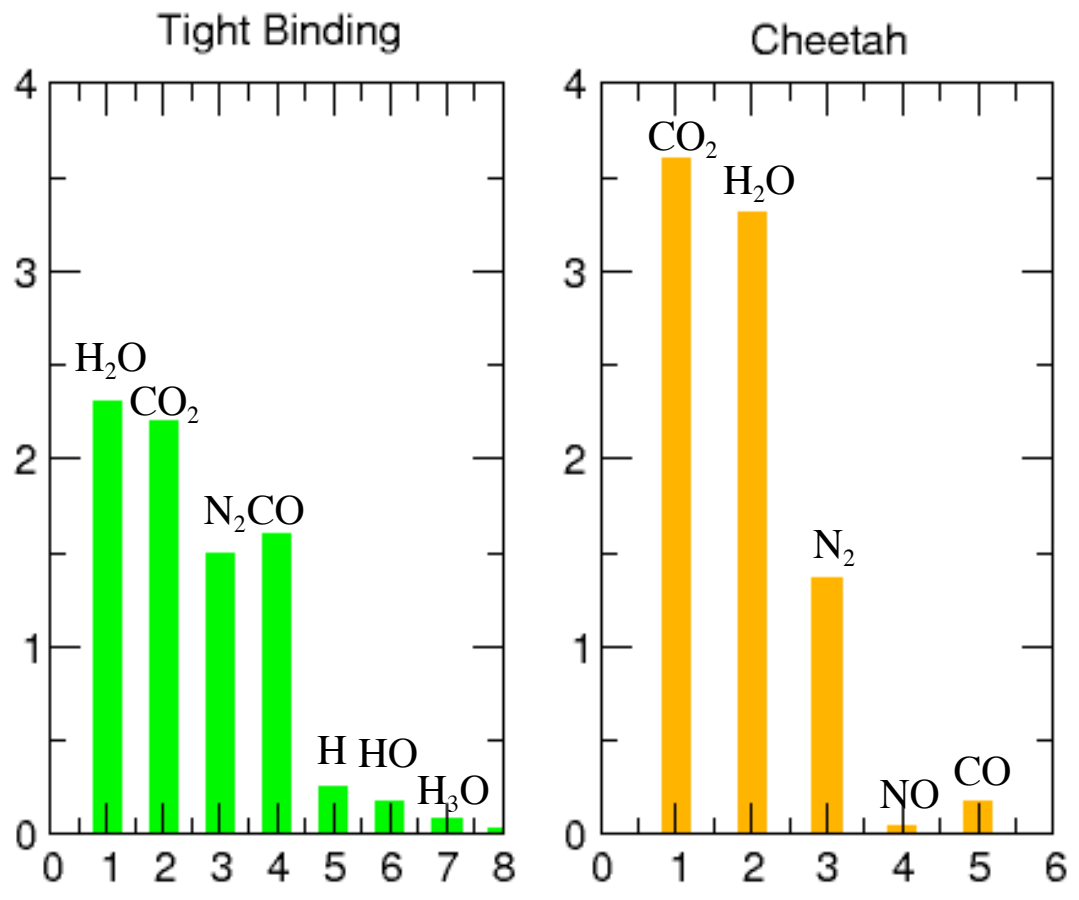

